\title{
Knee Osteoarthritis and Risk Factors Associated
}

\author{
Lamini N'Soundhat Norbert Edgard*, Mouelé Mboussi Paméla Chardène, \\ Nkouala-Kidédé Chabel Daphtone, Akoli Ekoya Ondzala, Ntsiba Honoré
}

Rheumatology Department, Brazzaville University Teaching Hospital, Brazzaville, Republic of Congo

Email: *nlamini@yahoo.fr

How to cite this paper: Edgard, L.N.N., Chardène, M.M.P., Daphtone, N.-K.C., Ondzala, A.E. and Honoré, N. (2017) Knee Osteoarthritis and Risk Factors Associated. Open Journal of Rheumatology and Autoimmune Diseases, 7, 147-152.

https://doi.org/10.4236/ojra.2017.73014

Received: June 24, 2017

Accepted: August 1, 2017

Published: August 4, 2017

Copyright $\odot 2017$ by authors and Scientific Research Publishing Inc. This work is licensed under the Creative Commons Attribution International License (CC BY 4.0).

http://creativecommons.org/licenses/by/4.0/

\begin{abstract}
Objective: Report of risk factors associated to knee osteoarthritis to improve management and functional prognosis of patients. Methods and patients: Transversal and analytic survey conducted in Brazzaville University Teaching Hospital (Congo) on 13,041 patients between 2000 and 2012. The diagnosis of knee osteoarthritis was done before a mechanical knee pain and radiological signs according to Kellgren and Lawrence criterias. The functional disability has been appreciated by Lequesne functional pain rate. Results: 200 patients, 42 men (21\%), 158 women (79\%), sex ratio was 0.26 . The average age was 57.4 years old, extremes were $25-82$ years. The knee osteoarthritis predominated between 60 and 69 years for men (38\%) and 50 - 59 years old for women (36\%). Body mass index (BMI) average was $29.98 \mathrm{~kg} / \mathrm{m}^{2}$. Co morbidities associated were arterial high blood pressure in 106 patients (53\%) and diabetes mellitus (28.5\%) and alcohol consumption (28\%). Tobacco addiction was associated in $12 \% .72 .15 \%$ of women were post-menopausal, with an average length of menopause at 9.6 years. Obesity (45.5\%) and overweight (35.5\%) were associated with genu varum in $58.7 \%$ and genu valgum in $40.1 \%$. Joint fluid was report in $30.5 \%$. The functional disability evaluated by Lequesne functional pain rate was superior to 8 for more of $50 \%$ of patients. The knee osteoarthritis was mainly secondary in $81 \%$. Conclusion: Age more than 57 years, female sex and menopause, obesity, genu varum or genu valgum, cardiovascular risk factors, were the main risk factors associated. Diagnosis was done too later and patients had an improvement functional disability.
\end{abstract}

\section{Keywords}

Knee Osteoarthritis, Genu Valgum, Genu Varum

\section{Introduction}

Knee osteoarthritis is the most frequent member's osteoarthritis in sub-Saharan Africa with an evolution to a bad functional prognosis. Knee prothetic surgery is not available in most developing countries. It leads to severe pain and disability 
development. Knee osteoarthritis is the first improvement after 50 years old in Africa [1] and its level prevalence is related between 33\% and 50\% after more than 60 years [2]. In Africa, populations socio economics' privacy associated to the difficulties of access to quality cares, makes that patients consult too late, often at a very evolved and invalidity stages. For that, in Western and developing countries, they act before installation of distortions and invalidity. These actions begin by identification and management of risk factors associated to this invalidating osteoarthritis. So, we intended to study the most risk factors associated to the knee osteoarthritis, in order to improve management and therefore, functional prognosis of our patients.

\section{Patients and Method}

It was a transversal and analytic study, conducted on medical files of thirteen thousands and forty one $(13,041)$ patients, followed in consultation and in hospitalization in rheumatology and traumatology-orthopedics' departments of the university teaching hospital of Brazzaville in Congo, from July 2000 to July, 2012, during 12 years. Diagnosis of knee osteoarthritis has been done on clinical arguments and x-ray, when a mechanical painful of knee were notified, with or without trouble of the statics of legs and on $\mathrm{x}$-ray of the knees, narrowed of cartilage, condensation of the joint surfaces and marginal osteophytis, according to Kellgren and Lawrence criterias [1]. Functional disability has been appreciated by Lequesne pain functional rate: for a score between 0 and 7 , handicap was considered as means, between 8 and 10 as important, between 11 and 13 as very important and finally beyond 14 as extreme, intolerable. Surgical indication as being carried for a Lequesne score superior to 10. Two hundred patients (200) have been kept, with hospitable frequency of $8 \%$. The software ear data version 16 permitted collections of data and software SPSS 11.5, statistical analysis. Quantitative variables have been expressed on average \pm gap-type. Qualitative variables have been expressed in strength and percentage. Ethic consent was obtained by patients and the study was approved by the National Ethics Committee.

\section{Results}

It was about 200 patients, 42 men (21\%) and 158 women (79\%) with a sex ratio was 0.26 . Average age was 57.4 years old, extremes of 25 and 82 years. The knee osteoarthritis predominated on men (38\%) between 60 and 69 years and between 50 and 59 years old on women (36\%). Forty four (44) patients (22\%) were less than 50 years old at the delay of diagnosis. The average delay of consultation was 4 years and 7 months. The Body mass index (BMI) was evaluated in 191 patients. The mean BMI was $29.98 \mathrm{~kg} / \mathrm{m}^{2} .68 .4 \%$ of men and $81.7 \%$ of women had a BMI superior or equal to $30 \mathrm{~kg} / \mathrm{m}^{2}$ (Table 1 ). The mechanical stress and traumatisms of knee were the main previous antecedents before apparition of knee osteoarthritis with respectively $73.5 \%$ and $13.5 \%$ of cases. Antecedents of inflammatory joint diseases of the knee and surgical acts represented only re- 
Table 1. Breakdown of patients according to sex and body mass index.

\begin{tabular}{ccccccc}
\hline \multirow{2}{*}{ Sex BMI } & \multicolumn{2}{c}{ Male } & \multicolumn{2}{c}{ Female } & \multicolumn{2}{c}{ Total } \\
\cline { 2 - 7 } & $\mathbf{n}$ & $(\%)$ & $\mathbf{n}$ & $(\%)$ & $\mathbf{n}$ & $(\%)$ \\
\hline Normal & 12 & $(31.6)$ & 28 & $(18.3)$ & 40 & $(21)$ \\
Overweight & 14 & $(36.8)$ & 50 & $(32.7)$ & 64 & $(33.5)$ \\
Obesity & 12 & $(31.6)$ & 75 & $(49)$ & 87 & $(45.5)$ \\
Total & $\mathbf{3 8}$ & $(19.9)$ & 153 & $(80.1)$ & 191 & $(100)$ \\
\hline
\end{tabular}

spectively $6 \%$ and $5 \%$ of cases. About co morbidities, arterial high blood pressure was the main cardiovascular factor associated to knee osteoarthritis, found among 106 patients (53\%), followed respectively by diabetes mellitus and consumption of alcohol in $28.5 \%$ and $28 \%$ of cases. The tobacco addiction was associated in $12 \%$ of cases. $114 / 158$ women in our series (72.15\%), were post menopausal at the time of knee osteoarthritis diagnosis, with an average length of menopause at 9.6 years. Pain was the main call sign. It came with a lameness in $90.5 \%$ of cases $(\mathrm{n}=181)$, crunch in $87.5 \%(\mathrm{n}=175)$ and avoidance in $27.5 \%$ of cases $(\mathrm{n}=55)$. Clinical pain location was more frequently bilateral $(54 \%)$. We found a genu varum deformity in $58.7 \%$ of cases $(n=108)$, genu valgum in $40.1 \%(n=65)$ and synovial fluid in $30.5 \%$ of cases $(n=61)$. On $x$-ray, lesions were bilateral in $66.5 \%$ of cases and one-sided in $33.5 \%$ of cases. According to the Kellgren and Lawrence criteria, lesions were at stage 2 in $41.5 \%$ of cases, stage 3 in $21.7 \%$ and stage 4 in $2.8 \%$ of cases. One compartment was involved in $53.7 \%$ of cases, two compartments in $38.3 \%$ and three compartments only in $6.9 \%$ of cases. The functional evaluation by Lequesne pain functional rate was more than 8 on $50 \%$ of patients. It was considered as important in $43 \%$ of cases, very important in $27 \%$ and extreme in $8 \%$ of cases. Obesity was the most factors often associated. Indeed $54.7 \%$ of obese patients had a Lequesne pain functional rate superior to 11 . The knee osteoarthritis was mainly secondary. The secondary shapes represented $81 \%$ of cases against $19 \%$ of primitive knee osteoarthritis. The main etiologic factor of secondary knee osteoarthritis was axial deviations, presented on all of our patients. The other etiologic factors are represented in Figure 1.

\section{Discussion}

To approach the question of risk factors is a matter for process in health both preventive and curative management. Our study appears in secondary and tertiary objectives, since the patients who come in consultation already endure a knee symptomatic osteoarthritis disease, for which we must endeavor to limit progress, reduce or to warn functional handicap. Because of prothetic surgery is not available in our professional environment, reinforce more again us to need focus on the determining of risk factors and disease's evolution. As in Togo [3], Burkina Faso [4] and Ivory Coast [5], the knee osteoarthritis in Congo-Brazzaville occupies a major place in rheumatology department with a hospitable frequency 


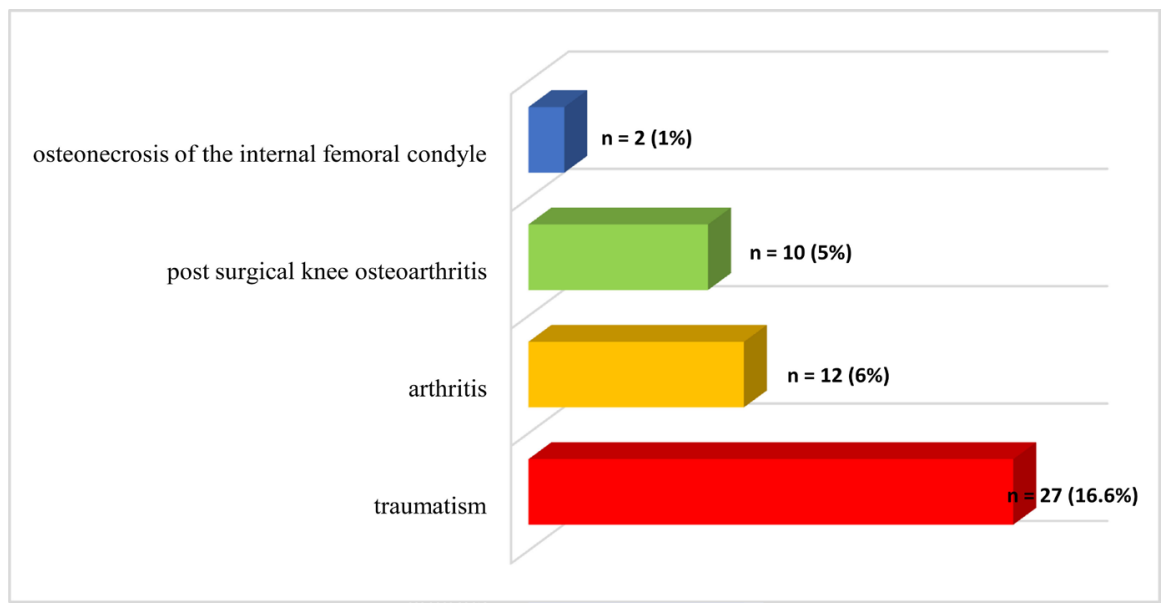

Figure 1. Breakdown of etiologic factors of secondary knee arthritis other than axial deviations.

of $8 \%$ in our series. Oniankitan et al. in Togo [3], reported the same and testified also a lot of problem of health in our countries. It mainly interests adult old more than 50 years, regardless of sex, as well as in Africa than in Europe [4] [6] [7]. Age is an important risk factor of knee osteoarthritis [8]. The frequency of this one increases with age as been shown by Felson et al. [9]. Women are more frequently attack than men, with a statistically meaningful difference. Menopause appears to be the main factor as suggested by Ouedraogo et al. [4] and Zhang and et al. [10]. Professional activity is another risk factor of knee osteoarthritis in our study. The domestic activities and farmers are the main incriminated in sub-Saharan Africa, contributing to explain the female predominance of knee osteoarthritis in our countries, where those activities are rather devolved to the women. Cardiovascular risk factors are frequently associated to knee osteoarthritis in African reports [4]. They essentially concern arterial high blood pressure, diabetes mellitus, overweight/obesity and alcohol consumption and tobacco addiction. Relation between frequency of cardiovascular risk factors and risk to develop knee osteoarthritis has been little studied. However, if we refer to Singh and al study [11], it seems that the populations affected by knee osteoarthritis have more cardiovascular risk factors. Indeed, they report a frequency of $40 \%$ for arterial high blood pressure, $32 \%$ for hypercholesterolemia, $20 \%$ for tobacco addiction and $11 \%$ for diabetes mellitus, compare with patients without osteoarthritis respectively in $25 \%, 24 \%, 26 \%$ and $6 \%$ of cases. Sedentary lifestyle, hyper caloric corollary diet of the obesity, itself a risk to develop diabetes mellitus and arterial high blood pressure can explain frequency of these cardiovascular risk factors in our set. Improvement of the knee osteoarthritis in our report is very important. In $72.8 \%$ of patients, it is more than to 8 according to Lequesne functional pain rate that indicates account of joint deterioration. Obesity is the most frequently factor associated. The role of obesity in the knee osteoarthritis has been established in West by many studies [12] [13]. This tie between obesity and knee osteoarthritis even persists after correction of metabolic troubles associated to the obesity [3]. If in our study, obesity appears asso- 
ciated with a severe handicap, like related by Ouedraogo et al. [4], axial deviations seem to be the main factor. Their high frequency in the study, $87.4 \%$, grants them a high level, in the evolution of the knee osteoarthritis, although it is difficult to say if they are cause or complication of it. The place of legs static troubles is very important in our series. Although we didn't study relation between obesity, legs static deformities and functional disability, it's likely that static disorders and obesity participate to explain the importance of joint narrowing. Although there is no clinical and radiological correlation, the low frequency of severe radiographic damage (Kellgren and Lawrence stage 4) is surprising to the view of frequency of legs axial deviations and obesity, as well as predominance in one compartmental shape, contrary to other African series [4] [6].

\section{Conclusion}

Knee osteoarthritis is frequent in our practice. Patients are most often seen too late, with important joint damages associated with genu varum or genu valgum. The Lequesne functional pain rate has a high level. Age, female sex, obesity, axial legs deformities and cardiovascular risk factors were the main risk factors of knee osteoarthritis. Joint prothetic replacement is not available in our countries.

\section{References}

[1] Richette P. (2005) Arthrosis. Revue du Praticien, 55, 1933-1942.

[2] Bagge, E., Bjelle, A., Valkenburg, H.A. and Svanbord, A. (1992) Prevalence of Radiographic Osteoarthritis in Tow Elderly European Populations. Rheumatology Internal, 12, 33-38.

[3] Oniankitan, O., Fianyo, E. and Mijiyawa, M. (2009) Osteoarthritis of the Knee in Hospital Outpatients in Lomé (Togo). Mali Médical, 24, 4-6.

[4] Ouédraogo, D.D., Séogo, H., Cissé, R., Tiéno, H., Ouédraogo, T., Nacoulma, I.S. and Drabo, Y.J. (2008) Risk Factors Associated with Osteoarthritis of the Knee in a Rheumatology Outpatient Clinic in Ouagadougou, Burkina Faso. Médecine Tropicale, 68, 597-599.

[5] Eti, E., Kouakou, H.B., Daboiko, J.C., Ouali, B., Ouattara, B., Gabla, K.A., et al. (1998) Aspects Epidemiology and Features of Knee Osteoarthritis in the Ivory Coast. Revue du Rhumatisme (English Edition), 65, 766-770.

[6] Singwe, N.M., Emche, M.C.B., Ntsiba, H., Ongolo, Z.P., Biwole, S.M., Ndobo, P., et al. (2007) Clinical and Radiological Aspects of Knee Osteoarthritis in Yaoundé. African Journal of Medicine, 5, 317-323.

[7] Iqbal, M.N., Haidri, F.R., Motiani, B. and Mannan, A. (2011) Frequency of Factors Associated with Knee Osteoarthritis. Pakistan Journal of Medicine Association, 61, 786-789.

[8] Andrianakos, A.A., Kontelis, L.K., Karamitsos, D.G., Aslanidis, S.I., Georgountzos, A.I., Kaziolas, G.O., et al. (2006) Prevalence of Symptomatic Knee, Hand, and Hip Osteoarthritis in Greece. The ESORDIG study. Journal of Rheumatology, 33, 2507-2513.

[9] Felson, D.T., Naimark, A., Anderson, J., Kazis, L., Catelli, W. and Meenan, R.F. (1987) The Prevalence of Knee Osteoarthritis in Elderly. The Framingham Os- 
teoarthritis Study. Arthritis Rheumatism, 30, 914-918.

https://doi.org/10.1002/art.1780300811

[10] Zhang, Y. and Jordan, J. (2010) Epidemiology of Osteoarthritis. Clinical Geriatric Medicine, 26, 355-369. https://doi.org/10.1016/j.cger.2010.03.001

[11] Singh, G., Miller, J.D., Lee, F.H., Pettitt, D. and Russell, M.W. (2002) Prevalence of Cardiovascular Disease Risk Factors among US Adults with Self-Reported Osteoarthritis: Data from the Third National Health and Nutrition Examination Survey. American Journal of Management Care, 8, 383-391.

[12] Wills, A., Black, S., Cooper, R., et al. (2012) Life Course Body Mass Index and Risk of Knee Osteoarthritis at the Age of 53 Years: Evidence from the 1946 British Birth Cohort Study. Annals of Rheumatism Diseases, 71, 655-660.

https://doi.org/10.1136/ard.2011.154021

[13] Michael, J.W.P. and Shlüter-Brust, K.U. (2010) The Epidemiology, Etiology, Diagnostic and Treatment of Osteoarthritis of the Knee. Deutsches Arzteblatt International, 107, 156-162.

Submit or recommend next manuscript to SCIRP and we will provide best service for you:

Accepting pre-submission inquiries through Email, Facebook, LinkedIn, Twitter, etc. A wide selection of journals (inclusive of 9 subjects, more than 200 journals) Providing 24-hour high-quality service User-friendly online submission system Fair and swift peer-review system Efficient typesetting and proofreading procedure Display of the result of downloads and visits, as well as the number of cited articles Maximum dissemination of your research work

Submit your manuscript at: http://papersubmission.scirp.org/ Or contactojra@scirp.org 